\title{
EL CUERPO COMO VIA MYSTICA EN ALGUNOS TEXTOS DE BLAKE Y DE VIEL TEMPERLEY*
}

Fecha de recepción: 22 de febrero de 2014

Fecha de aprobación: 24 de marzo de 2014

\section{Resumen}

Las características de la poesía de Héctor Viel Temperley han hecho de él un poeta de gran predicamento en el contexto literario argentino actual. En ella, la exaltación del cuerpo, del deporte, de la sensualidad y la sexualidad constituyen una peculiar forma de búsqueda de lo sagrado. En este sentido, la poesía del autor de Hospital Británico guarda similitudes con la inquietante lírica de William Blake. Aunque el tenor de la producción de Viel Temperley es diferente de la del inglés, hay en ambas una misma actitud de exaltación del cuerpo como vía de acceso a lo sagrado. En el presente trabajo, abordaré algunos textos de ambos autores como muestras de una mística del cuerpo.

Palabras clave: Poesía; Literatura latinoamericana; Mística; Viel Temperley; Blake.

* Artículo de reflexión. El presente artículo es, con algunas modificaciones, el trabajo de investigación del seminario "Poéticas en la literatura argentina. Representación, imaginarios y modos de figuración", dictado por la Dra. Susana Cella (Universidad de Buenos Aires) en la Universidad del Salvador en 2013.

Citar: Cárcano, E. (julio - diciembre de 2014). El cuerpo como via mystica en algunos textos de Blake y de Viel Temperley. La Palabra (25), 81-92

\section{Enzo Cárcano}

Consejo Nacional de Investigaciones Científicas y Técnicas (CONICET), Argentina Universidad del Salvador (USAL), Argentina enzo.carcano@usal.edu.ar

Becario de posgrado del Consejo Nacional de Investigaciones Científicas y Tecnológicas (CONICET), doctorando en Letras en la Universidad del Salvador; Máster en Lengua Española y Literaturas Hispánicas por la Universitat de Barcelona, con un trabajo sobre la poesía de Jacobo Fijman; Corrector literario, Profesor y Licenciado en Letras por la Universidad del Salvador. Actualmente, trabaja, en esta misma institución, como investigador del Instituto de Investigaciones de Filosofía y Letras y como profesor auxiliar de Seminario de Literatura Argentina y de Teoría Literaria. Es miembro del Comité Ejecutivo de la Colección La Vida en las Pampas, que dirige la Dra. María Rosa Lojo en Editorial Corregidor. 


\title{
THE BODY AS VÍAMYSTICA IN SOME TEXTS BY BLAKE AND VIELTEMPERLEY
}

\begin{abstract}
The characteristics of Héctor Viel Temperley's poetry have made him a prestigious poet in the Argentinian literary current context. In this poetry, the exaltation of the body, sport, sensuality and sexuality, do not contradict but makes a peculiar way of search for the sacred. In this sense, the poetry of the author of Hospital Britanico is related to William Blake's disturbing poetry. Obviously, the tenor of both poetic outputs are different, but a similar attitude towards the body and its exaltation as a way of purification can be noticed in both. In this article, I will study some texts of both authors as examples of a body mystic.
\end{abstract}

Key Words: Poetry; Latin American Literature; Mystics; Viel Temperley; Blake.

\section{LE CORPS COMME VOIE MYTHIQUE DANS QUELQUES TEXTES DE BLAKE ET DE VIEL TEMPERLEY.}

\section{Résumé}

Les caractéristiques de la poésie d'Hector Viel Temperley ont fait de lui, un poète d'un grand prestige dans le contexte littéraire argentin actuel. Dans cette poésie-là, l'exaltation du corps, du sport, de la sensualité et de la sexualité non seulement la contredisent, mais constituent, une forme particulière de chercher ce qui est sacré. Dans ce sens, la poésie de l'auteur de l'Hôpital Britannique garde des similitudes avec l'inquiétante lyrique de William Blake. Bien que la teneur de la production de Viel Temperley soit différente de celle de l'anglais, les deux ont une même attitude d'exaltation du corps en tant que voie d'accès à ce qui est sacré. Dans ce travail, on abordera quelques textes des deux auteurs, en tant qu'échantillons d'une mystique du corps.

Mots clés: Narrative argentine de la fin du XIXème siècle, autonomie de la femme, positivisme, libéralisme économique. 
The head Sublime, the heart Pathos, the genitals Beauty, the hands $\&$ feet Proportion.

William Blake, The Marriage of Heaven and Hell

Soy el nadador, Señor, solo el hombre que nada.

Gracias doy a tus aguas porque en ellas mis brazos todavía hacen ruido de alas. Héctor Viel Temper-

ley,

"El nadador"

\section{Introducción}

Aunque tardíamente descubierta por gran parte del público y de la crítica, la producción poética de Héctor Viel Temperley, publicada íntegramente en 2003, dieciséis años después de la muerte del autor, suscita hoy el interés de gran cantidad de lectores, académicos o no. La razón de este fenómeno, muchas veces cercano a la fascinación o al culto, parece estribar en las características de esta poesía: la exaltación del cuerpo, del deporte, de la sensualidad y la sexualidad constituyen una peculiar forma de búsqueda de lo sagrado. Con razón, la crítica ha señalado con distintos motes, la originalidad de esta búsqueda ${ }^{1}$. En el presente estudio, sin pretender contradecir las interpretaciones que ya se han hecho de la poesía de Viel Temperley, propongo leerla en relación con la inquietante épica de William Blake; en particular, con The Marriage of Heaven and Hell. Aunque, obviamente, el tenor de la producción de Viel Temperley no es, como la de su par inglés, afín al hermetismo ni constituye toda una mitología sincrética, puede verse en ambas una misma actitud de exaltación del cuerpo como vía de purificación, de acceso a lo sagrado. Este rasgo, según entiendo, constituye el aspecto central de la lírica de Viel Temperley y, por tanto, puede ser visto como una de las razones de su notable originalidad: como propugna Blake, el yo lírico supera la división y alcanza la purificación mediante la paulatina entrega al deseo, a la energía, a la vida, rasgo que se realiza de modo más acabado en Legión extranjera (1978) y en Crawl (1982).

\section{Sobre el yo lírico}

En la poesía de Viel Temperley, la búsqueda de lo sagrado se articula con ciertos elementos que han llevado a algunos a afirmar, sin demasiado rigor, que él fue, en efecto, un místico, y que su producción es una prueba de ello. Sin ánimo de extenderme demasiado en consideraciones teóricas, debo aclarar que, en el presente trabajo, entenderé, desde una perspectiva pragmática, a la poesía como discurso cuya configuración textual misma es ficcional (Pozuelo Yvancos, 1997, p. 262). En tanto forma particular de comunicación literaria, la lírica supone la fictivización del autor, es decir, su desdoblamiento, la delegación de la enunciación en un hablante lírico que no puede ni debe ser identificado con el autor empírico o real. En síntesis, consideraré en lo sucesivo al yo lírico de la poesía de Viel Temperley como una entidad ficcional, una estrategia textual pergeñada por el autor que no puede ni debe ser identificada linealmente con él, ni es, por tanto, prueba suficiente para afirmar una hipotética experiencia mística del hombre Héctor Viel Temperley. Aunque es cierto que, en muchos casos, la cercanía del yo lírico con el yo empírico es palmaria y no es ilícito señalar esta vecindad, la tarea de la crítica no debe quedarse en concluir o rastrear estas similitudes, o en explicar uno a partir del otro. Como bien señala Scarano en un interesante trabajo titulado "La alucinación de la referencia”, quizá convenga entender la cuestión de la relación de

1 María Gabriela Milone habla de una mística corrida de lugar (2003, p. 29); Cristina Piña, de una mística extraterritorial (2011 y 2013); Walter Cassara, de una intensa mística fálico-amorosa (2011, p. 9). 
esta con la ficción “...como una operación discursiva que funciona como representación verbal de lo real con un espesor propio, que cancela la antigua sospecha de identidad" (2000, p. 104). Lo principal, según entiendo, es no ignorar la constitución de la textualidad, de la hechura artística de la obra poética. Esto, desde ya, no busca impugnar la existencia de una intención detrás de la obra - el poeta, el autor-, sin cuyo impulso creativo esta no existiría.

\section{Sobre la mística}

La voz mística, del griego $\mu v \sigma \tau v \kappa o ́ s$, procede (como las voces $\mu v ́ \sigma \tau \eta \varsigma$, 'el que inicia', o $\tau \alpha \mu v ́ \sigma \tau v \kappa \alpha$, 'lo relativo a los misterios') de la combinación de la raíz griega $\mu v$ con el verbo $\mu v ́ \omega$, que significa 'cerrar, especialmente la boca o los ojos'. De esta acepción inicial de 'cerrado', el término pronto adquiere el sentido de 'secreto', 'misterio', tanto en el terreno de lo relativo a la religión como en el profano (Sainz Rodríguez, 1961, pp. 48-61). Como sustantivo, mística aparece recién a principios del siglo XVII, y designa, desde entonces, una manera de hablar particular, un lenguaje novedoso, un modus loquendi (Certeau, 2006, pp. 86 y ss.). Esta sustantivación es de importancia significativa, ya que abre un nuevo espacio, un ámbito específico desde el cual abordar el estudio de las obras de aquellos que, desde entonces, comenzarán a ser - aun retroactivamente - denominados místicos.

En relación con los trabajos que tienen a la mística como objeto de estudio, dos son los abordajes que, tradicionalmente, han tenido más predicamento: el esencialismo, cuya idea directriz es que existe una sola e idéntica experiencia mística con variaciones que no afectan esa unicidad (entre los autores que han abonado esta opción epistemológica, muy afín al comparatismo, se encuentran, entre otros, Evelyn Underhill, Rudolf Otto y Robert Charles Zaehner); y el constructivismo, que sostiene, por el contrario, que no existen dos experiencias místicas iguales (Katz, 1978, p. 65), ya que esta, como todas las experiencias humanas, está sometida al condicionamiento de procesos formativos y lingüísticos de índole cultural, de modo que no la interpretación del sujeto acerca de su experiencia, sino la realización y configuración de la experiencia misma, de su "sustancia", está determinada por el sujeto y su pertenencia a una determinada cultura (Velasco, 2009, pp. 35-42).

En los últimos años, se han intentado otros abordajes que moderan las afirmaciones de esencialistas y constructivistas: desde la fenomenología de la religión, desde la psicología, desde la historiografía. En el presente trabajo, como queda dicho, rechazo la idea de estudiar la obra de arte de un autor como prueba de su hipotética experiencia mística, por lo que, al hablar de la mística de Viel Temperley, me inclinaré por la escueta pero sumamente operativa definición de Isabel Cabrera — resultado, según ella misma reconoce, de un proceso de "generalización inductiva"“...entendemos por mística la búsqueda de la unión con (o disolución en) lo sagrado", definido esto último como "...el presunto objeto al que remite la experiencia religiosa [que] queda vagamente descrito con la expresión 'misterio liberador o salvífico"' (2006, p. 12). Esta idea de Cabrera, nacida del propósito de “...reflexionar sobre la naturaleza de la mística sin pronunciar[se] acerca de la existencia o inexistencia de su objeto ni, por consiguiente, acerca de su verdad" (2006, p. 9), nos permitirá, a la vez, hablar de una mística en el caso de la lírica de Viel Temperley y permanecer en el plano textual. Este abordaje no busca impugnar -ni siquiera se plantea la posibilidad de su estudio desde el ámbito de la crítica literaria - la presunta experiencia mística de Héctor Viel Temperley hombre (fenómeno que, entiendo, le corresponde a otras disciplinas - la teología, la filosofía, la an- 
tropología, la psicología, entre otras-). Podría argüirse que la especificidad de la poesía mística es, en efecto, el estar escrita solo por hombres y mujeres que han tenido una experiencia trascendente, pero esto nos llevaría a una crítica biografista poco rigurosa. Cierto es que esta correspondencia se presuponía —aún más, se daba por evidente- en algunos de los contextos históricos en los que la poesía mística floreció. Pero los contextos y los modos de lectura que estos posibilitan y generan, cambian. Leer la mística hoy de igual modo como se hacía, por ejemplo, en el Medioevo, cuando la única preocupación era el arreglo o no del contenido de sus escritos con la doctrina defendida por la Iglesia, sería, por lo menos, inconducente.

\section{Una mística del cuerpo}

Contra lo que suele creerse, las poéticas que se encuadran en lo que antes denominamos "mística" no están relegadas a la Edad Media, ni al Renacimiento, ni a los ámbitos eclesiásticos o devotos. Aunque su enfoque diverge del que he planteado, la siguiente apreciación de Luce López Baralt sugiere la extensión de este fenómeno: “...una experiencia actual y vivísima, que resulta, de otra parte, mucho más repartida e incluso más laica de lo que suele creerse. A menudo se da [...] al margen de las vías místicas 'reglamentarias' y aun de la estricta santidad individual" (pp. 11-12).

Ni la poesía de Blake ni la de Viel Temperley, como ninguna poesía mística, son expresión de una recta doctrina institucional. Si bien la del primero es harto más heterodoxa y combativa que la del segundo, en la que no hay visos de una intención reformadora, ambas se desvían —al menos en algo- de los cánones trazados por las autoridades eclesiásticas de sus tiempos y lugares. La peculiar actitud de un yo lírico que busca a Cristo en su propio cuerpo, en la sexualidad, en el amor por una mujer, en la natación, a la vez que sorprende por su atipicidad, hace de la producción de Viel Temperley una poco dogmática, al igual que la de tantos que han sido catalogados históricamente como poetas místicos. Al respecto, el cabalista Gershom Scholem señala que estos "Se inclina[n] ante la autoridad con una veneración piadosa, pero esa inclinación apenas alcanza a encubrir el hecho de que realmente la está[n] transformando, a menudo de una manera audaz e, incluso, a veces, extremada" (2009, p. 27). Quizá podríamos aplicar esta apreciación a la poesía de Viel Temperley, aunque decididamente no a la de Blake, creador él mismo de una heteróclita y compleja mitología incompatible con doctrina alguna. En cualquier caso, lo importante es el carácter audaz y renovador de esas manifestaciones lingüísticas que reciben el calificativo de místicas. Pero en los casos de Blake y Viel Temperley, esa originalidad propia de la mística se completa con la centralidad que en sus obras ocupa el cuerpo.

Para poder hablar de una mística del cuerpo, debemos considerar a este, de modo similar a como lo hiciera el fenomenólogo francés Maurice Merleau-Ponty, como la dimensión ontológica fundamental a partir del cual se establece toda relación con el mundo. Según este pensador, no existe una diferencia tal como cuerpo/alma: "La unión del alma y del cuerpo no viene sellada por un decreto arbitrario entre dos términos exteriores [...]. Esta unión se consuma a cada instante en el movimiento de la existencia" (1994, p. 107). El hombre es, en este sentido, cuerpo consciente y consciencia corporal. Ese vértice borroso en el que se dibuja en el entrelazamiento de lo visible y lo invisible, del cuerpo y del alma, es, para Merleau-Ponty, la carne: "La chair du monde [...] est indivisión de cet être sensible que je suis et de tout le reste qui se sent en moi"'2 (Merleau Ponty, 1964, p. 309). De este modo, la 
carne pontiana es un quiasmo que incluye cuerpo y alma, ser y percepción. Para llegar a la mística, ese cuerpo no solo debe ser vehículo de acceso al mundo, sino que también debe ser vía de acceso a lo sagrado, sea este entendido en un plano extraterreno (Viel Temperley) o no (Blake). De este modo, el cuerpo es no solo la trama a través de la que el hombre llega a conocer el mundo y a relacionarse con él, sino también, y fundamentalmente, es el medio que el hombre tiene para llegar a lo divino: cuanto más aparece el yo lírico situado en el mundo, exacerbando sus sentidos, más cerca está de lo sagrado.

Llegados a este punto, podríamos pensar que, si el cuerpo es via mystica, ello se debe, necesariamente, a que él mismo también es ausencia, falta de lo que no contiene en sí. Y la mística es la expresión de esta falta y de la búsqueda que ella genera. Como señala Ángel Gabilondo, "La carne es siempre experiencia de ausencia de plenitud, experiencia de necesidad de lo otro en sí, de falta" (1992, p. 61); y la mística es "...el lenguaje de la carne, en la medida en que es el acceso de la carne a la intemperie, la exhibición de la carne" (1992, p. 70). Aunque Gabilondo no sigue aquí el concepto de carne pontiano, resulta sugerente su visión de la mística como la expresión de la ausencia intrínseca a la corporalidad: la carne es falta esencial, constitutiva, y a la vez, anhelo de encuentro. Y la mística es la posibilidad, en el lenguaje, de esa unión (Gabilondo, 1992, p. 69).

No obstante lo dicho, aunque la mística del cuerpo es, de algún modo, una erótica, un volver la mirada hacia sí, hacia el propio cuerpo y el deseo, sería difícil situarla en el nivel de la experiencia interior de George Bataille. En esta, el sujeto llega al extremo de lo posible, al desgarro interior, para encontrar lo sagrado como puro sacrificio, como una presencia ausente o una ausencia presente: se trata de esa nueva teología que no tiene más objeto que lo desconocido (Bataille, 1973, p. 110). Sin embargo, en la mística del cuerpo que propongo, hay una afirmación positiva de lo sagrado, que, aun cuando no sea más que un misterio, es uno liberador. En este punto me distancio de la tesis sostenida por Milone, para quien la mística de Viel Temperley es, siguiendo a Bataille, teopática, ateológica e invertida, ya que las menciones concretas de lo sagrado ("Dios", "Jesucristo", "Cristo") aparecen indefinidas, desprovistas de las cargas doctrinales o dogmáticas que se esperarían en la mística tradicional (Milone, 2014, pp. 173 y ss.). Por un lado, creo que la definición -intencionalmente generalizadora- de "mística" que he señalado antes en este trabajo permite sortear la cuestión de si esta búsqueda se da conforme a los cánones de un credo institucionalizado o no, hecho que, si bien es importante para la compresión de ciertas producciones que han llegado a ser referencias de la mística en el mundo occidental (San Juan de la Cruz, Santa Teresa de Jesús, Meister Eckhart, entre tantos otros), no es requisito necesario para que la búsqueda sea efectiva. Por otro lado, aunque hay tradiciones místicas, entiendo que es difícil hablar de mística tradicional, aunque esas tradiciones compartan numerosos rasgos. Por último, como intentaré exponer - aunque solo sea brevemente- en lo que sigue, la figura de Cristo resulta esencial a la mística del cuerpo de los poetas de los que aquí me ocupo, ya que Él, dios y hombre, es visto como la posibilidad antonomástica del cuerpo sacralizado.

2 "La carne del mundo [...] es la indivisión de este ser sensible que soy yo y de todo aquello que se siente en mí". 


\section{Blake}

Aunque la mitología imaginativa que William Blake, "discípulo rebelde de Swedenborg" al decir de Borges (1989, p. 399), desplegó en sus textos no tiene "prototipo ni paralelo", se funda, como otras de raíces gnósticas, en el principio que asocia el bien con la unidad y el mal con la fragmentación. El pecado original fue, justamente, el paso de un estado al otro: el hombre, una parte de la totalidad, quiso orgullosamente ser autosuficiente y prevalecer sobre el resto de la creación (Abrams, 1992, p. 255). Si la caída es la división, la resurrección será, inversamente, la vuelta a la unidad. $\mathrm{Y}$ es precisamente aquí donde interviene lo corporal. Estas ideas alcanzan su realización más clara en The Marriage of Heaven and Hell.

Entre muchas de las dicotomías, impuestas por el pensamiento racionalista y las leyes (las leyes del hombre, aquellas que son producto de su activi- dad regulatoria), que el hombre debe superar para acceder a la totalidad, está la oposición cuerpo/alma. Para Blake la adoración de lo humano, de lo corporal, su divinización, es una forma de adorar a Dios. Del mismo modo, el deseo es la energía que de él viene, y aquel que la reprime no es, como el deseante, un hombre prolífico, sino uno que genera "pestilencia": "He who desires but acts not, breeds pestilence"3 (2009, p. 136). Esta energía de la que habla Blake solo puede ser seguida por aquellos que superan la dualidad impuesta por el pensamiento racionalista, por las instituciones, por los códigos:

\section{The Voice of the Devil ${ }^{4}$}

All Bibles or sacred codes have been the causes of the following Errors:

1. That Man has two real existing principles: Viz: a Body \& a Soul.

2. That Energy, call'd Evil, is alone from the body; and that Reason, call'd Good, is alone from the Soul.

3. That God will torment Man in Eternity for following his Energies.
But the following Contraries to these are True:

1. Man has no Body distinct from his Soul; for that call'd Body is a portion of Soul discern'd by the five Senses, the chief inlets of Soul in this age.

2. Energy is the only life, and is from the Body; and Reason is the bound or outward circumference of Energy.

3. Energy is Eternal Delight ${ }^{5}$ (2009, pp. 130 y 132).

En la poesía visionaria de Blake, la vida es goce, es exuberancia energética, y el seguimiento del deseo, el único modo de superar la fragmentación impuesta por la razón y alcanzar así lo sagrado. El que es puro se entrega a la sexualidad, al cuerpo, y no reprime su deseo. Como bien señala George Bataille en La littérature et le mal, en Blake, "La pierre de touche [...] est la joie des sens. La sensualité l'oppose au primat de la raison. Il condamne la loi morale au nom de la sensualité [...].Son œuvre appelle résolument le bonheur sensuel, la plénitude

3 "Quien desea pero no obra engendra peste" (Blake, 2009, p. 137).

4 En la línea de John Dee, para Blake, Satán es aquel que, al desobedecer a Dios, siguió su propio deseo y, así, obedeció a la creación. En este sentido, en la cosmovisión blakeana, la mención del diablo no entraña sentido negativo.

5 "La voz del Diablo

Todas las Biblias o códigos sagrados han sido la causa de los Errores siguientes:

1. Que el Hombre posee dos principios reales de existencia: un Cuerpo y un Alma.

2. Que la Energía, llamada Mal, sólo nace del Cuerpo y que la Razón, llamada Bien, sólo nace del Alma.

3. Que Dios atormentará al Hombre en la Eternidad por seguir sus Energías.

Mas los Contrarios siguientes son Verdaderos:

1. El Hombre no tiene un Cuerpo distinto de su Alma; pues lo que llamamos Cuerpo es una porción de Alma discernida por los cinco Sentidos, las puertas principales del Alma en esta edad.

2. La Energía es la única vida y nace del Cuerpo; y la Razón es el límite o circunferencia periférica de la Energía.

3. Energía, Eterno Deleite" (Blake, 2009, pp. 131 y 133). 
exubérante des corps" (1957, p. 163).

Jesucristo es la encarnación de este tipo de hombre y la muestra de que la divinidad y la humanidad son, al menos desde Él, inseparables. Él desafió la Ley y a los maestros del templo, y predicó el Amor. Él se convierte siempre de acuerdo con la visión blakeana- en Jehová, la versión misericordiosa del colérico dios del Antiguo Testamento. A Jesucristo - $\mathrm{y}$ esto es de capital importancia- el hombre debe buscarlo a través de sí, de su cuerpo, de las pequeñas cosas de la creación - tan recurrentes en la producción temprana de Blake, Songs of Innocence y Songs of Experience- y no en el dogma, en la Ley, en las instituciones reguladoras de la actividad humana. El final del The Marriage of Heaven and Hell, en el que un demonio y un ángel discuten sobre la figura de Jesucristo, es una buena muestra de este pensamiento:

"Thou Idolater! is not God One? \& is note he visible in
Jesus Christ? and has not Jesus Christ given his sanction to the law of ten commandments? and are not all other men fools, sinners, \& nothings?".

The Devil answer'd: "bray a fool in a morter with wheat, yet shall not his folly be beaten out of him; if Jesus Christ is the greatest man, you ought to love him in the greatest degree; now hear how he has given his sanction to the law of ten commandments: did he not mock at the Sabbath and so mock the sabbath's God? murder those who were murder'd because of him? turn away the law from the woman taken in adultery? steal the labor of others to support him? bear false witness when he omitted making a defence before Pilate? covet when he pray'd for his disciples, and when he bid them shake off the dust of their feet against such as refused to lodge them? I tell you, no virtue can exist without breaking these ten commandments. Jesus was all virtue, and acted from impulse, not from rules" 7 (2009, pp. 160 y 162).

Este pasaje condensa la reivindicación de la figura de Jesús que se propone Blake; su actitud rebelde, contraria a la ley pero favorable al deseo, es decir, a su propia humanidad. Jesús es, en síntesis, la figura más acabada del hombre puro, prolífico, del que lleva en sí la unidad inicial: "Así como la caída del hombre es 'su caído en la División' y la muerte, así su redención [...] es 'su Resurrección en la Unidad'. El principio unificador es Jesús..." (Abrams, 1992, p. 256).

La mística del cuerpo aparece en la épica de Blake no como un elemento atípico, sino como el único camino para acceder a lo sagrado, que él identifica con la unidad perdida. Jesucristo, hombre y dios, es la figura que garantiza la posibilidad de redención. Pero esta debe ser buscada no por medio de la ascesis y la negación de lo sensible que imponen las instituciones eclesiásticas — que no conciben la pureza del alma sin la purgación del cuerpo- o mediante la lógica que apela a la hipertrofia de la razón, sino a través del camino del deseo, de la celebración de lo corporal. Esta mística del cuerpo es el único modo que concibe Blake de ser consecuentes con

6 "La piedra de toque [...] es la alegría de los sentidos. Opone la sensualidad al primado de la razón. Condena la ley moral en nombre de la sensualidad [...]. Su obra propugna resueltamente la felicidad sensual, la plenitud exuberante de los cuerpos".

7 “«Tú, Idólatra! ¿ंAcaso no es Dios uno? ¿No es Él visible en Jesucristo?, y Jesucristo ¿no hay dado su sanción a la ley de los diez mandamientos? ¿No son todos los otros hombres necios, pecadores, nadas?».

El Demonio contestó: «Muele a un necio en un mortero con el trigo y aún así su necedad no se separará de él. Si Jesucristo es el más grande de los hombres deberías amarlo con el amor más grande. Pues bien, escucha de qué manera sancionó la ley de los diez mandamientos: ¿No se burló del Sábado, del Sábado de Dios? ¿No mató a aquellos que fueron muertos por su casa? ¿No ignoró la ley de la mujer sorprendida en adulterio? ¿No robó el trabajo de otros para sostenerse? ¿No cayó en falso testimonio al rehusar defenderse de Pilatos? ¿No codició cuando pidió por sus discípulos y cuando los incitó a apartarse de aquellos que rehusaren darles albergue? Por eso te digo: no hay virtud posible que no rompa esos diez mandamientos. Jesús era todo virtud y obraba por impulsos, no por reglas»" (Blake, 2009, pp.161 y 163). 
Dios y con la totalidad que él representa.

\section{Viel Temperley}

Lejos de esta idea de una unidad perdida de raigambre gnóstica, la poesía de Viel Temperley, sin embargo, coincide con la de Blake no en el concepto de lo sagrado, pero sí —y de modo notable- en el modo por medio del cual este es buscado. Si bien en la producción temprana de Viel Temperley el yo lírico se detiene más en la naturaleza, ya aquí el cuerpo y su relación con ella y con los elementos es central": "Aire, agua, tierra, concurren a la fogosa explosión en una imagen donde se sueldan los elementos con el cuerpo habitado por el ángel" (Cella, 2011, p. 19). No obstante, es en dos de los últimos poemarios, Legión extranjera y Crawl, entre los que media un proceso de transformación (más formal que temática) ${ }^{9}$, en los que mejor se adivinan los rasgos capitales de la mística del cuerpo que hace de la lírica de Viel Temperley una de rotunda originalidad en la tradición latinoamericana.

Aunque en la tradición mística cristiana la purgatǐo, la ascesis necesaria para acceder a la comunicación trascendente, se asocia a la noche de los sentidos, en la poesía de Viel Temperley, la purificación implica una actitud contraria por parte del yo lírico: el exceso de las potencias corporales, esa "natación de Dios" de la que hablaba Tamara Kamenszain (2000, p. 155-159), todo lo que recuerda a algunos Proverbios del Infierno de Blake, "The road of excess leads to the palace of wisdom"10 (2009, p. 134), "The lust of the goat is the bounty of God"11 (2009, p. 138). A propósito, sirva como ejemplo el siguiente poema notablemente bleakeano- de Humanae vitae mia (1969):

\footnotetext{
Qué horror el paraíso

Qué horror el paraíso si Adán no bubiera amado la carne de su carne, si hubiera descubierto que era una carne aparte, enemiga de las alas.

Hubiera comido la manzana como quien se purga.

Hubiera sido padre
}

de pueblos y de razas (Viel Temperley, 2003, p.101. Los destacados son nuestros).

En esta composición, el hablante reivindica el accionar de Adán, el gran pecador, como hombre, como padre, como sujeto amante de la carne, de la carne de su carne. Esta celebración del cuerpo y del deseo puede verse, con mayor o menor intensidad, en toda la producción de Viel Temperley, pero alcanza su expresión más acabada en Legión extranjera y, especialmente, en Crawl. Del primero, cito un fragmento de "Equitación":

Las obligaba a mantenerse
erguidas y a hablar así mi-
rándome a los ojos a pesar
del pudor sin derramarse
hacia mi cuerpo inmóvil
como amazonas en la silla
cómodas pero estribando
corto. Y al paso al trote o
nuevamente al paso cada
vez que el silencio me en-
frentaba o entre nubes de
arena divisaba volando una
nueva cometa rasante pe-
ligrosa de una valla a otra
valla las oía
Y las primeras veces que
ocultando sus pechos y sus
rostros caían sus cabellos
eran mis manos las que los
separaban porque al comien-

8 Las relaciones entre El arma, poemario de 1953 incluido en Poemas con caballos, de 1956, y la visión blakeana del cuerpo, resulta notable. A propósito de ese libro, Walter Cassara afirma: “...subvierte, ya desde sus comienzos, las figuras de la poesía mística, a tal punto que ya no se trata [...] de una retórica femenina de la comunión nupcial, sino de la eucaristía narcisista y solitaria de una macho pánico donde, extrañamente, es el alma la que ocupa la posición fálica, la que empuña y desposa, se diría incluso que desflora, al cuerpo abierto como un río, una cuenca o vulva anonadada" (2011, p. 10).

9 En la entrevista que le hizo Sergio Bizzio poco antes de morir, Viel Temperley señala: “....yo tenía la intención de romper mi poesía; la notaba demasiado rígida, como atada a un molde, un principio, un medio, un fin: sabía qué iba a decir. Después pasé a decir, a ver, empezó a interesarme la poesía que me permitía no solamente esconderme sino evadirme y hacer un mundo, tener un mundo (58)".

10 "El camino del exceso lleva al palacio del saber" (Blake, 2009, p. 135).

11 "Lujuria del chivo, generosidad de Dios" (Blake, 2009, p. 139). 
zo no se atreven a tocárselos siquiera y para hablar sin luz se sirven de ellos como de las rejillas de los confesionarios (Viel Temperley, 2003, pp. 290-291).

Respecto de este poema, bien dice Silvio Mattoni que no hacen falta lecturas alegóricas, "...porque literalmente la escena sexual es una aparición de lo trascendental en un momento mínimo: mujeres que hablan mientras cabalgan el sexo del narrador..." (2011, p. 92). No es la represión del deseo sino la entrega a él a través del cuerpo, de la sexualidad, lo que hace que el yo lírico acceda a lo sagrado, a lo salvífico, como sucede también en "La casada y la vela" ("Y hay un falo que es mío que es solamente mío:/ Pero el amor es más que un falo que jamás se comparte!” [2003, p. 303]) o en "Bajo las estrellas del invierno" ("Pero una liebre un pájaro una perra/ me miraron a los ojos al corazón al sexo/ como creo que sólo me miró también el mar" [2003, p. 306]). A través de la revivificación de experiencias pasadas, el yo lírico, a veces inquirido por un tú difuso, adivina lo sagrado en su propio cuerpo y en su goce: "Príncipe inmóvil de las peluquerías/ o/ Hombre que fornica mientras espera el Reino?” (2003, p. 311), dicen los últimos versos de "El prefacio", pieza inaugural de "Aquí amanece gris y el viento trae violetas", tercera parte de Legión extranjera.

En Crawl, el cuerpo como vehículo para llegar a lo sagrado no solo se traduce en la visión del yo lírico, sino también - y este es uno de los mayores atractivos del poemario- en la forma, en la disposición de los versos sobre la hoja. El mismo Viel Temperley explica la géneris del libro:

\begin{abstract}
Si mirás Crawl arriba es como un cuerpo que va nadando. Yo desplegaba el poema en el suelo y me paraba en una silla para ver dónde había algo que se saliera del dibujo. Me pasaba horas arriba de la silla fumando y mirando, y corrigiendo para que tuviera esa forma. Incluso trato de que las estrofas no tengan puntos hasta la tercera parte, porque quería que fuera un respirar, quería que cada brazada fuera una respiración. Solamente al final, cuando habla con otros hombres, hay puntos y cortes. Pero, donde es pura natación, son estrofas (Bizzio, 1987 , p. 58).
\end{abstract}

De este modo, el desplazamiento de los versos, separados con espacios en blanco y con distintos márgenes, busca representar un cuerpo que nada y que, en sus brazadas y su respirar, encuentra su ritmo. Ese nado, esa "inmersión en el éxtasis de la comunión" de la que habla Alicia Genovese (2011, p. 47), es un cuerpo que, en toda su actividad, en el goce de la actividad física, alcanza a encontrar allí —en sí-a Jesucristo:
Vengo de comulgar y estoy en éxtasis

-De los labios colgado, o de la hostia-,

hospital retraído respirando; Y, sangre en celosía, en ella dejo pulsos, piel, carcajadas de cosacos

Que de mohamed no aceptan ser vasallos, hasta besarme el Rostro en Jesucristo

Detrás de los cabellos del vago en la arena, donde los confesores no caminan,

En mi conciencia, que tragué - sacrílego-

con Él, que ve el limón,

la cal, el sexo

. . .

En las costas del yo, que en sus muros enyesa

. . .

Ya en Él, que hace mi ahora entre costillas

— como vendas de espacios sin memoria-

(Viel Temperley, 2003, pp. 349-350. El destacado es del autor)

En este breve pasaje - $-\mathrm{y}$ en el breve poemario que lo contiene- se condensa la mística corporal de la lírica de Viel Temperley. En el primer verso, repetido al comienzo de cada una de las tres partes del libro, el yo lírico declara su estado extático que, sin embargo, no le impide besarse el rostro en Cristo, es decir, sentirlo en su propio cuerpo. Porque Jesús, después de todo, es, en esta poesía, el dios hombre, el que no reclama la renuncia de los sentidos, sino que se presenta en su celebración, en el goce sensual:

Remolco sobre el hielo a una muchacha

Y sé que lo que hicimos refulgía y llamaba —ahora 
sé-mientras lo hacía-

mos.

Y yo no era su prójimo, ni mi yo era mi prójimo, (Viel Temperley, 2003, pp. 360-361)

Hospital Británico, el último y más comentado poemario de Viel Temperley, es probablemente el más complejo de toda su producción. Aquí, fragmentos de los cuatro libros anteriores (Humana vitae mia, Carta de marear, Legión extranjera y Crawl) se alternan con pasajes compuestos, según la "Nota" final, entre 1984 y 1986, años en los que el autor fue tratado por un tumor cerebral. En Hospital Británico, así como el yo lírico está desdoblado cronológicamente, el cuerpo aparece representado como cuerpo enfermo pero jamás pierde su carácter de vehículo de y hacia lo sagrado. Así el yo lírico reconocerá a su cuerpo, en ocasiones hermanado al de Cristo — quien también aparece como la madre moribunda- como meta: "Voy hacia lo que menos conocí en mi vida: voy hacia mi cuerpo. (1984)" (2003, p. 374). Las alusiones al cuerpo en estos sentidos son numerosas. Para no extenderme demasiado, citaré solo un par de pasajes que, según creo, reflejan el tono de este último poemario:

\section{Tengo la cabeza vendada \\ (textos proféticos) \\ Mi cuerpo — con aves como}

bisturíes en la frente- entra en mi alma. (1984) (Viel Temperley, 2003, p. 381)

Tengo la cabeza vendada (texto del hombre en la playa)

El sol entra con mi alma en mi cabeza (o mi cuerpo con la Resurrección- entra en mi alma). (1984)

(Viel Temperley, 2003, p. 382)

. . .

Quiero beber hacia mi nuca, eternamente, los dos brazos del ancla del temblor de $\mathrm{Tu}$ Carne y de la prisa de los Cielos. (1984)

(Viel Temperley, 2003, p. 382)

. .

El Reino de los Cielos me rodea. El Reino de los Cielos es el Cuerpo de Cristo —y cada mediodía toco a Cristo.

(Viel Temperley, 2003, p. 383)

Como si aquel proverbio infernal de Blake que reza "Joys impregnate. Sorrow bring forth"12 (2009, p. 138) se hiciera poesía en Hospital Británico, aquí el cuerpo maltrecho del yo lírico, que es ahora un trepanado, se hace uno con su alma y se prepara para dar a luz una nueva vida de unión con lo sagrado, con el Cuerpo de Jesucristo. En este último poemario en el que se adivina el fin de la búsqueda del hablante ${ }^{13}$, el cuerpo se disuelve o, como afirma Milone, "se derrama" en Dios (2003, p. 58).

\section{Conclusión}

Contrarias a la conocida via mystica cristiana casi institucionalizada (purgatǐo, illuminatǐo y unĭo) — que no por difundida es el único modo de concebir la experiencia mística-, las obras de William Blake rechazan de plano la renuncia de los sentidos, de la carne y del placer, y celebran el deseo, entendido como la satisfacción de la energía concedida por Dios. Para el autor de The Marriage of Heaven and Hell, el cuerpo no es la cárcel del alma; ni siquiera se contrapone a ella. Por el contrario, la grandeza de espíritu y el acceso a lo sagrado solo son para aquellos que se entregan incondicionalmente al deseo, para los hombres prolíficos. Si bien la poesía de Viel Temperley no constituye, como la del inglés, toda una mitología, sí comparte el rechazo de la doctrina institucional y la celebración de lo corporal como puerta a lo salvífico. En este sentido, la figura de Jesucristo, que aparece como la síntesis perfecta de lo humano y lo divino, es el modelo a seguir, la referencia con la que identificarse.

Creo que el estudio de las relaciones intertextuales entre la poesía del autor de Crawl y la de Blake, así como su emplazamiento en un marco como el de la mística del cuerpo que he propuesto, permite comprender otros rasgos de la originalidad de tales producciones.

12 Recordemos la sugerente lectura de Kamenszain, quien se refiere a Hospital Británico como una lírica terminal (2000, p. 145). 13 "El gozo fecunda. El dolor engendra" (Blake, 2009, p. 139). 


\section{Referencias}

Abrams, M. W. (1992). El Romanticismo. Tradición y revolución. Tomás Segovia, trad. Madrid: Visor.

Bataille, G. (1973). La experiencia interior. Fernando Savater, trad. Madrid: Taurus.

Bataille, G. (1957). La littérature et le mal. París: Gallimard.

Bizzio, S. (1987). Viel Temperley: estado de comunión. Vuelta Sudamericana (12), 58-59.

Blake, W. (2009). Antología bilingüe (Caracciolo Trejo, E. trad.). Madrid: Alianza Editorial.

Borges, J. L. (1999). Obras completas. 1975-1985. Buenos Aires: Emecé.

Cabrera, I. (2006). Para comprender la mística. En: Cabrera, I. y Silva. C. Umbrales de la mística (pp. 9-25). México D.F.: UNAM.

Cassara, W. (2011). En las templadas aguas del origen. En: Cassara, W., Cella, S. y otros. Viel Temperley (pp. 9-14). Buenos Aires: Ediciones del Dock.

Cella, S. (2011). La refracciones del líquido amniótico: Héctor Viel Temperley. En: Cassara, W., Cella, S. y otros. Viel Temperley (pp. 15-35). Buenos Aires: Ediciones del Dock.

Certeau, M. (2006). La fábula mística (siglos XVI-XVII) (Colell, L., trad.). Madrid: Siruela.

Gabilondo Pujol, Á. (1992). La mística como lenguaje de la carne. Edad de Oro, (9), 59-71.

Genovese, A. (2011). Leer poesía. Lo leve, lo grave, lo opaco. Buenos Aires: Fondo de Cultura Económica.

López Baralt, L. (1996). Prólogo. La experiencia mística: tradición y actualidad. En: López Baralt, L y Piera, L. El sol a medianoche. La experiencia mística: tradición y actualidad (pp. 9-22). Madrid: Trotta.

Kamenszain, T. (2000). Historias de amor. (Y otros ensayos de poesía). Buenos Aires, Paidós.

Katz, S. (1978). Mysticism and Philosophical Analysis. Nueva York: Oxford University Press.

Mattoni, S. (2011). Nueve libros en busca de un estilo. En: Cassara, W., Cella, S. y otros. Viel Temperley (pp. 8898). Buenos Aires: Ediciones del Dock.

Merleau Ponty, M. (1994). Fenomenología de la percepción. Barcelona: Planeta-Agostini.

Merleau Ponty, M. (1964). Le visible et l'invisible. París: Gallimard.

Milone, M. G. (2003). Héctor Viel Temperley. El cuerpo en la experiencia de Dios. Córdoba: Ferreyra Editor.

Milone, M. G. (2014). Pensamiento filosóficos y experiencias religiosas en la poesía argentina contemporánea. Córdoba, Argentina: Universidad Nacional de Córdoba.

Piña, C. (2013). Héctor Viel Temperley: de márgenes, exclusiones y extraterritorialidades. Gramma (50). En prensa.

Piña, C. (2011). Viel Temperley, el místico extraterritorial. En: Cassara, W., Cella, S. y otros. Viel Temperley (pp. 121-135). Buenos Aires: Ediciones del Dock.

Pozuelo Yvancos, J. M. (1997). Lírica y ficción. En: Garrido Domínguez, A. Teorías de la ficción literaria (pp. 241-268). Madrid: Arco Libros.

Sainz Rodríguez, P. (1961). Espiritualidad española. Madrid: Rialp..

Scholem, G. (2009). La cábala y su simbolismo. José Antonio Pardo, trad. México D.F.: Siglo xxi Editores.

Velasco, J. M. (2009). El fenómeno místico. Estudio comparado. Madrid: Editorial Trotta.

Viel Temperley, H. (2003). Obra completa. Buenos Aires: Ediciones del Dock. 